\title{
Systems Design, Fabrication, and Testing of a High-Speed Miniature Motor for Cryogenic Cooler
}

\author{
Dipjyoti Acharya, ${ }^{1}$ Lei Zhou, ${ }^{1}$ Liping Zheng, ${ }^{1}$ Thomas X. Wu, ${ }^{1}$ \\ Jay Kapat, ${ }^{1}$ Louis Chow, ${ }^{1}$ and Nagaraj K. Arakere ${ }^{2}$ \\ ${ }^{1}$ Department of Mechanical, Materials, and Aerospace Engineering, University of Central Florida, 4000 Central Florida Blvd,
Orlando, FL 32816, USA
${ }^{2}$ Mechanical \& Aerospace Engineering, University of Florida, Gainesville, FL 32611, USA
}

Correspondence should be addressed to Louis Chow, lchow@mail.ucf.edu

Received 13 June 2009; Revised 20 September 2009; Accepted 12 October 2009

Recommended by Yasutomo Kaneko

The long-term storage of liquid hydrogen for space missions is of considerable interest to NASA. To this end, the Reverse TurboBrayton Cryocooler (RTBC) is considerably lighter than conventional designs and a potentially viable and attractive solution for NASA's long-term Zero-Boil-off (ZBO) hydrogen storage system for future space missions. We present the systems design, fabrication, and performance evaluation of the Permanent Magnet Synchronous Motor (PMSM) powering a cryocooler capable of removing $20 \mathrm{~W}$ of heat at $18 \mathrm{~K}$ with a COP of 0.005 and driven by two $2-\mathrm{kW}$ permanent magnet synchronous motors operating at $200000 \mathrm{rpm}$ and at room temperature and $77 \mathrm{~K}$. Structural, thermal, and rotordynamic aspects of system design are considered.

Copyright ( 2009 Dipjyoti Acharya et al. This is an open access article distributed under the Creative Commons Attribution License, which permits unrestricted use, distribution, and reproduction in any medium, provided the original work is properly cited.

\section{Introduction}

The Reverse Turbo-Brayton Cryocooler (RTBC) is a potential solution for NASA's long-term Zero-Boil-off (ZBO) hydrogen storage system for future space missions. The RTBC cryocooler can have similar thermal efficiency as the current state-of-the-art Liquid Hydrogen (LH2) cryocoolers with much less weight and size. The University of Central Florida (UCF) has had an ongoing research program in the past five years, funded by NASA GRC, to develop a miniature RTBC capable of removing $20 \mathrm{~W}$ of heat at $18 \mathrm{~K}$ with a coefficient of performance (COP) of 0.005 . The projected mass of the cryocooler is $\sim 20 \mathrm{~kg}$ which is an order of magnitude less than a commercially available GM cryocooler with a mass of $\sim 200 \mathrm{~kg}$. The UCF design focus has been on an integrated motor/compressor, which is a crucial component of the cryocooler. The design pressure ratio and ability to remove heat at $18 \mathrm{~K}$ necessitate a twostage compressor [1]. We have chosen to develop our motor and compressor in two phases. The first phase is to build a $200000 \mathrm{rpm}, 2 \mathrm{~kW}$ motor which is sufficient to power the first stage of the compressor. Figure 1 shows the developed permanent magnet synchronous motor (PMSM) with a 2-pole, 3-phase slotless structure. The selection of PMSM was based on its high efficiency due to low eddy current loss in the stator and rotor and no excitation power loss in the rotor. Novel features of the motor include the incorporation of high energy density permanent magnet, multistrand twisted Litz wires to reduce eddy current loss, slotless laminated stator to reduce torque pulsation, and creative optimal V/f control algorithm and advanced DSP for efficient motor control. The permanent magnet is centrally located inside the hollow shaft. For high-speed drive, 2-pole configuration is preferred since the required electrical frequency is the lowest for the same shaft speed. Low electrical frequency can reduce switching loss of the controller.

The electrical aspect of the motor has been published elsewhere $[2,3]$. In this paper, we will describe our efforts in resolving the mechanical design issues associated with the motor including rotordynamics and stress analysis. The permanent magnet motor has a hollow shaft with the magnet embedded in the center. Hard-mounted silicon nitride ball bearings ( $6.35 \mathrm{~mm}$ diameter) support the titanium shaft. A finite element model of the shaft-magnet system was built to ensure that the rotational stresses developed at high speed are within the yield strength limits of the permanent magnet and 


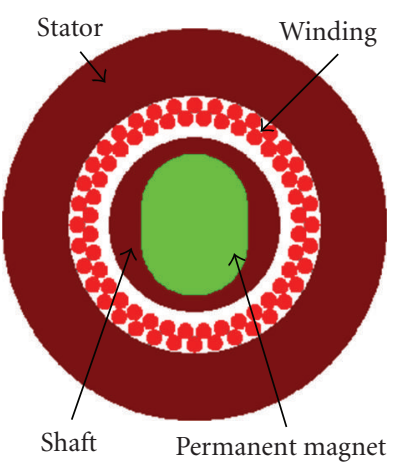

(a)

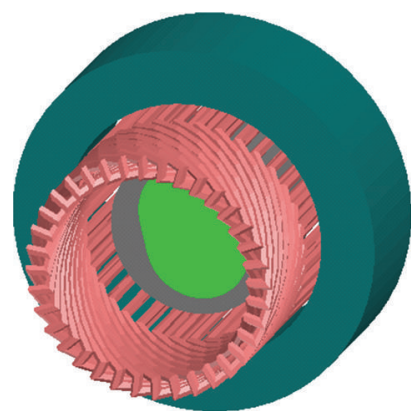

3D model of the winding

(b)

Figure 1: Configuration of the PMSM design.

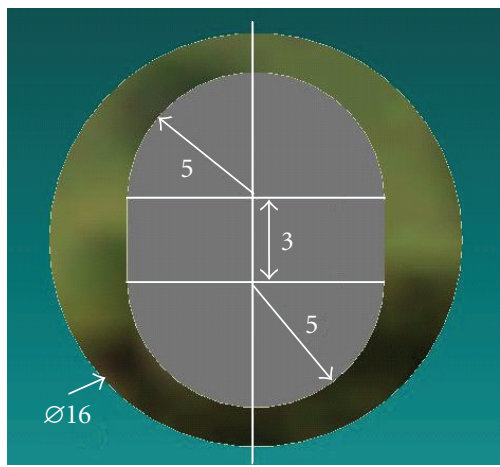

All dimensions are in $\mathrm{mm}$

Figure 2: Cross section of the hollow titanium rotor shaft used with a diameter of $16 \mathrm{~mm}$. The oval magnet is press-fit into the shaft.

shaft (titanium) materials. A rotordynamics model was built to predict the system critical speeds, unbalance response, and stability characteristics. The motor has been tested successfully up to $200 \mathrm{Krpm}$ without significant rotordynamics issues.

\section{Material Selection, Assembly, and Fabrication of the Rotor}

The criteria for design of the shaft were high yield strength nonmagnetic alloy to withstand the centrifugal and thermal stress developed while operating at $77 \mathrm{~K}$ and $200000 \mathrm{rpm}$. Titanium 6-4 was considered the most suitable choice as shaft material since it possesses a high yield strength value and low density, compared to other materials considered, such as Inconel and MP35N (Table 1). Titanium 6-4 has similar coefficient of thermal expansion as the magnet material SmCo which facilitates the assembly process which involves press-fitting the magnet into the hollow shaft [4]. Figure 2 shows the hollow titanium shaft/permanent magnet cross section with dimensions. Figure 3 shows the rotor components of the electric motor.

The permanent magnet design guidelines require that the magnet be subject to a compressive stress field during

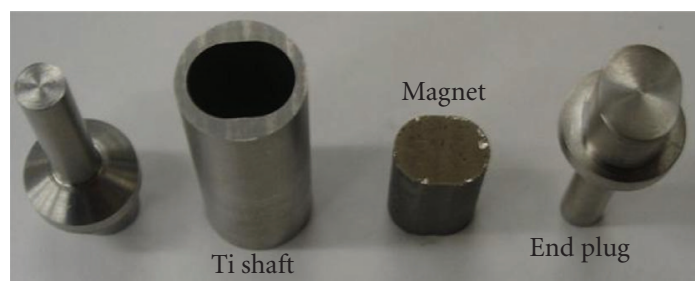

(a)

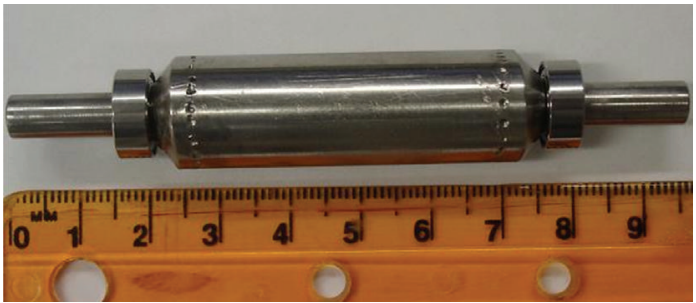

(b)

FIgURE 3: Rotor components of the motor (a) hollow titanium shaft (16 mm dia), titanium end plugs, SmCo magnet, and (b) assembled rotating shaft with silicon nitride ball bearings.

operation. Interference fit of at least $0.01 \mathrm{~mm}$ between the shaft and magnet is desirable at room temperature [5]. It was estimated that heating the shaft to $400^{\circ} \mathrm{C}$ and cooling the magnet to $77 \mathrm{~K}$ would produce the necessary differential clearance to insert the magnet in the shaft and eventual cooling would establish the interference fit. Titanium $6 \mathrm{Al}-4 \mathrm{~V}$ rotor was fabricated by Electro Discharge Machining process and is shown in Figure 3. Figure 4 shows the fabricated housing with the two end caps, rotor shaft, and the integrated rotor. Figure 5 shows the fabricated stator with the winding. Figure 6 shows the assembled PMSM with water cooling system.

A ceramic fixture shown in Figure 7 was used to assemble the shaft and magnet. The shaft was heated $400^{\circ} \mathrm{C}$ and placed on it as shown. The magnet was cooled to $77 \mathrm{~K}$ with Liquid Nitrogen being dropped inside shaft. The position of the magnet inside the shaft was located by the projected part from the fixture base. 
TABle 1: Properties of materials considered for the rotorshaft/magnet assembly.

\begin{tabular}{lcccc}
\hline Properties & Magnet SmCo & Titanium Ti-6Al-4V & Inconel 718SPF & MP35N \\
\hline Yield Strength MPa & 830 (in Compression) & 1400 & 1390 & 1620 \\
Density kg/m ${ }^{3}$ & 8500 & 4420 & 8220 & 8430 \\
CTE m/m. ${ }^{\circ} \mathrm{C}$ & $7 \times 10^{-6}$ & $9 \times 10^{-6}$ & $14 \times 10^{-6}$ & $12.8 \times 10^{-6}$ \\
\hline
\end{tabular}

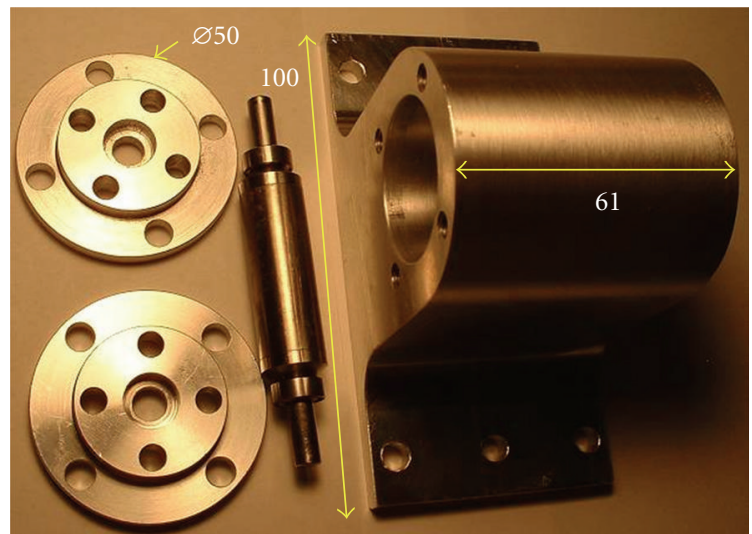

All dimensions are in $\mathrm{mm}$

FIgure 4: The fabricated housing, two end caps, rotor shaft, and the integrated rotor.

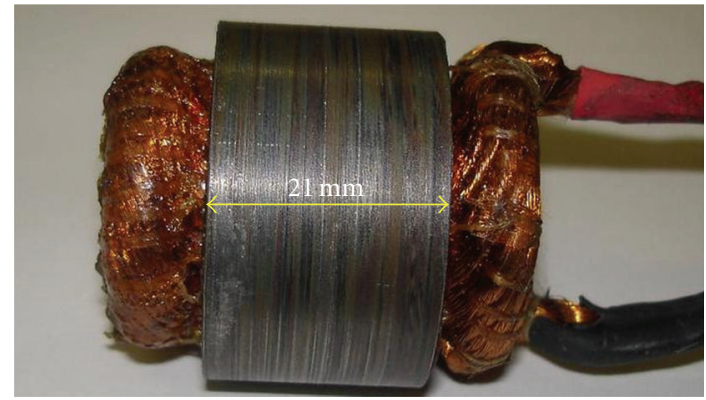

FIgURE 5: The fabricated stator with winding.

\section{Finite Element Stress Analysis of the Shaft/Magnet Assembly}

The shaft-magnet assembly was considered as a composite material with cross-section and dimensions shown in Figure 2. A finite element model of the shaft-permanent magnet assembly was built in commercial FEA software and stress analysis performed, to examine the component stresses due to shaft rotation, interference, and thermal effects. The oval shaped permanent magnet at the poles was press-fit into the hollow shaft, to avoid slip during rotation.

The stress fields generated in the shaft-magnet assembly due to rotation (body forces) and thermal loading were modeled. The close match of the CTE for the shaft and magnet materials ensures that temperature changes will not significantly change the assembly interference fit. However, the radial expansion of the titanium shaft and samarium cobalt magnet due to the rotational forces results in a

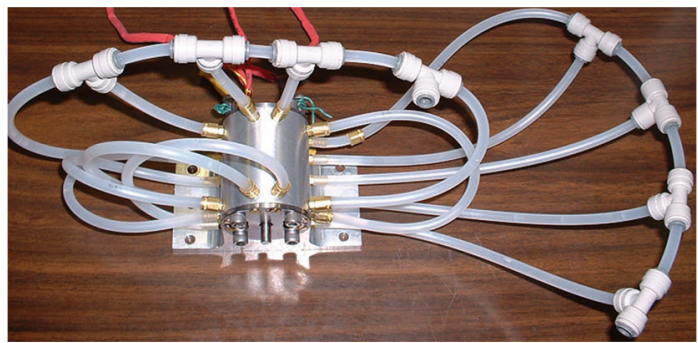

Figure 6: Assembled PMSM with water cooling system.

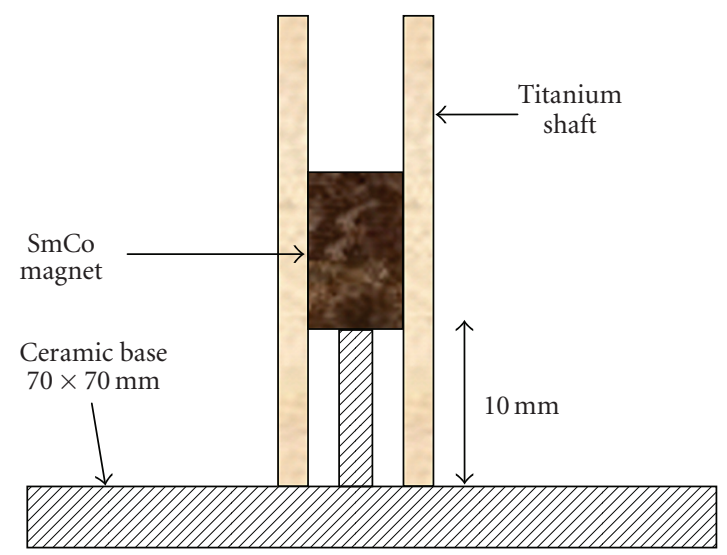

FIGURE 7: Shaft-magnet assembly procedure.

reduction in the assembly fit at operating speed $[6,7]$. As mentioned earlier, to ensure that there is a positive interference at all times the assembly interference fit was chosen to be $0.01 \mathrm{~mm}$ between the shaft and the permanent magnet. Figures 8 and 9 show the von Mises stress distribution in the shaft and magnet, respectively, at zero rpm and $200000 \mathrm{rpm}$, including the effect of interference. The maximum von Mises stress observed was much less than the yield strength of Ti 64 and magnetic materials used.

\section{Rotordynamic Analysis of Rotor}

Rotordynamics of high-speed flexible shafts is influenced by the complex interaction between the unbalance forces, bearing stiffness and damping, inertial properties of the rotor, gyroscopic stiffening effects, aerodynamic coupling, and speed-dependent system critical speeds. For stable high-speed operation bearings must be designed with the appropriate stiffness and damping properties, selected on the basis of a detailed rotordynamic analysis of the rotor system. A finite element rotordynamic model of the flexible rotorbearing system was built, as shown in Figure 10. The model 


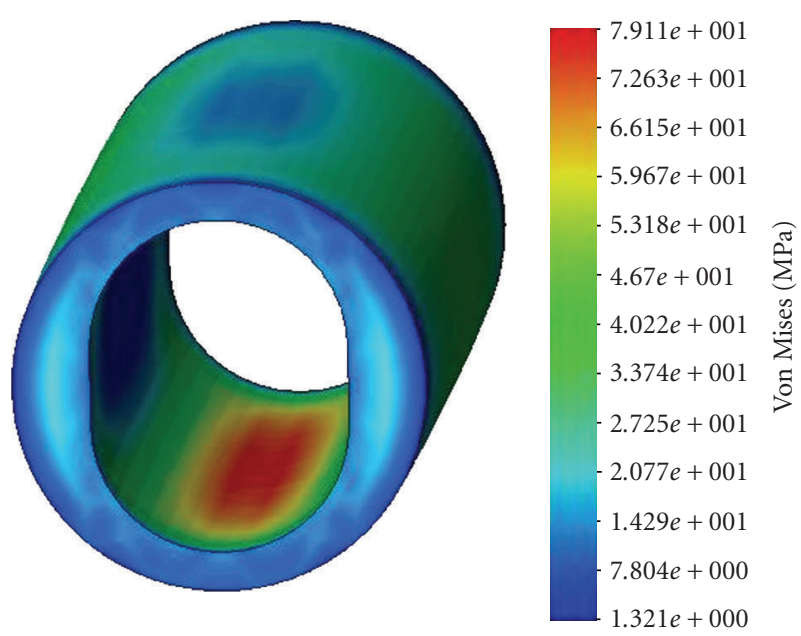

(a)

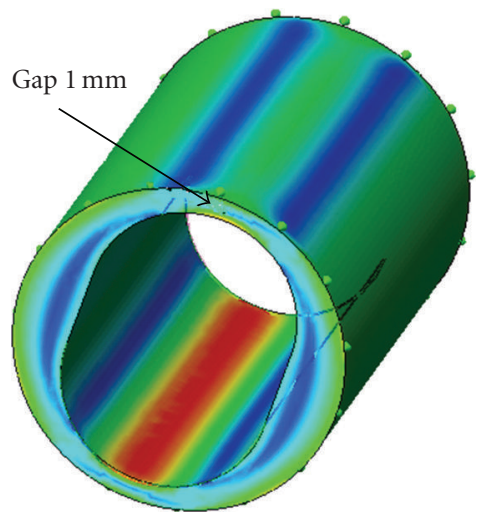

(b)

Figure 8: Von Mises stress distribution in shaft at (a) zero rpm and (b) $200000 \mathrm{rpm}$.

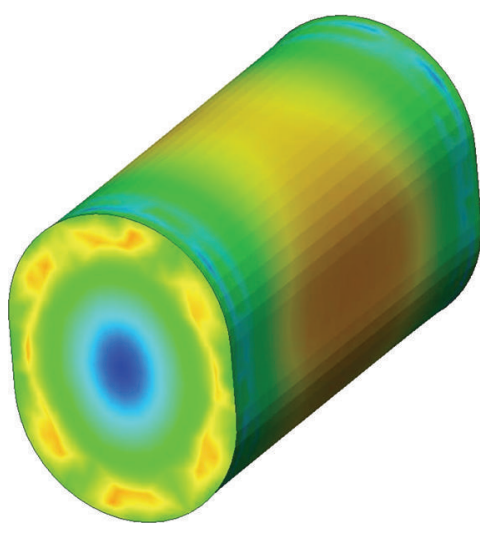

(a)

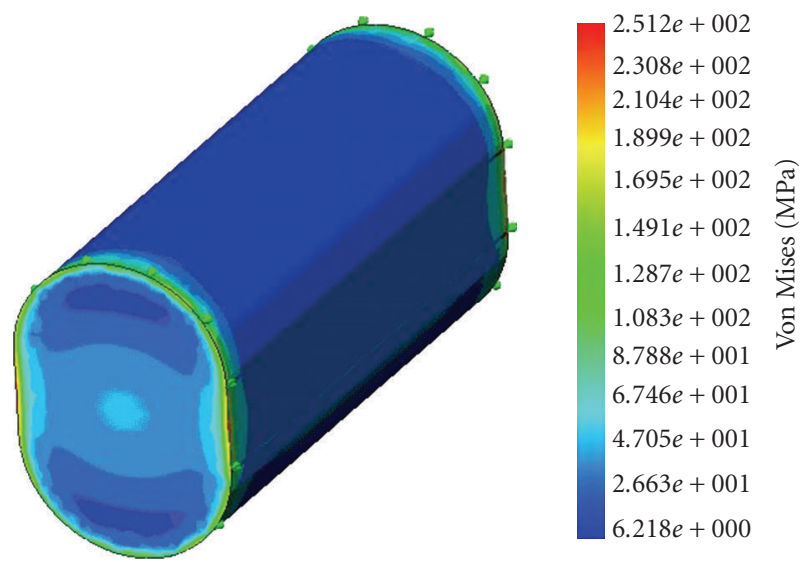

(b)

FIgURe 9: Von Mises stress distribution in magnet at (a) zero rpm and (b) $200000 \mathrm{rpm}$.

consists of 9 Timoshenko beam elements, 10 nodes, and 40 degrees of freedom (2 rotations and 2 displacements at each node). The cross section of the central rotor section is oval. However, the shaft is not really hollow since the oval permanent magnet that fits into the shaft hollow section has a strong interference fit. The end plugs also have an interference fit with the shaft. The stiffness of the overall shaft assembly with the interference fits effectively makes the shaft stiffness nearly isotropic and hence two natural frequencies in the two directions (in the rotating reference frame) were not discerned during experimentation. We also note that during rotation there is a high likelihood of microslip between the assemblies, due to forced unbalance vibratory response even with the interference fit, which will add coulomb friction damping to the system, and reduces resonant peaks during run up. There is no easy way to estimate this coulomb damping in the system. We also did not observe sharp resonances during system run up, as would be expected in a ball bearing system without squeeze-film

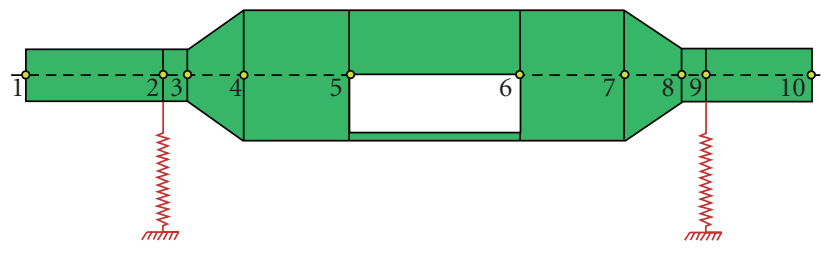

FIGURE 10: Schematic of the finite element rotordynamics model of the shaft. The hollowed section in the center indicates that the press fit magnet does not contribute to the stiffness in that element.

dampers, since the system damping is expected to be very low. This also indicates that the system damping available is more than from the ball bearings alone. Because of these considerations the isotropic stiffness of the assembly was considered appropriate.

The ball bearing support stiffness was estimated to be roughly $100000 \mathrm{~N} / \mathrm{mm}$, based on operating internal clearance and contact angle. Since bearing stiffness is a 


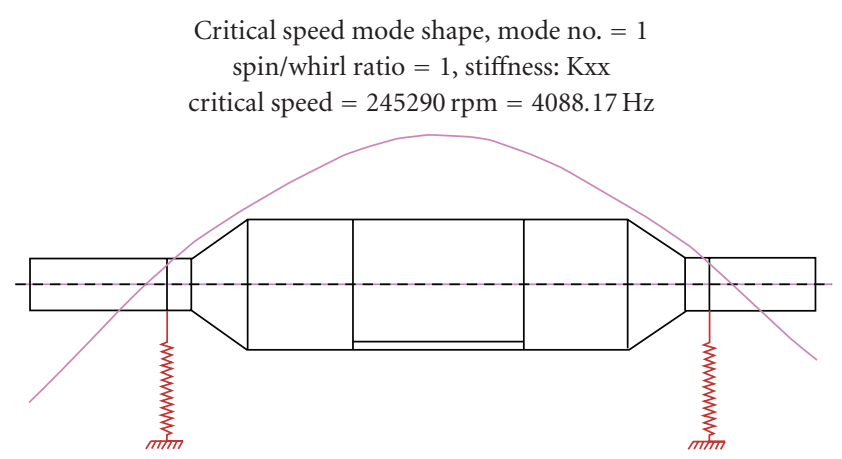

FIGURE 11: First bending critical speed for the rotor is $245290 \mathrm{rpm}$.

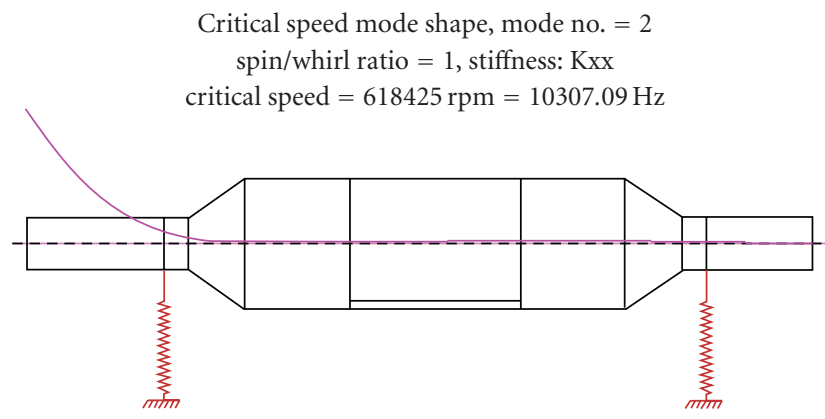

FIGURE 12: Second bending critical speed for the rotor is $618425 \mathrm{rpm}$.

sensitive function of operating internal clearance and load, bearing stiffness values used for analysis are approximate. The analysis predicts rigid and bending critical speeds, critical speed map, and unbalance response. The first bending critical speed is at $245290 \mathrm{rpm}$ and the second bending critical speed is at $618425 \mathrm{rpm}$, for a bearing stiffness of 100000 N/mm, as shown in Figures 11 and 12, respectively. The first bending mode is above the required operating speed of $200000 \mathrm{rpm}$, for the first-phase testing of this rotor system. Figure 13 shows the critical speed map of the system, illustrating the variation of the first 3 bending modes as a function of bearing stiffness. The first and second bending critical speeds are also shown in Figure 13 and correspond to the values in Figures 11 and 12. Figures 14 and 15 show the unbalance response of shaft at 110000 and $200000 \mathrm{rpm}$, respectively, with assumed unbalance of $0.001 \mathrm{~kg} \mathrm{~mm}$ at finite element nodes 4 and 7. Balancing specifications for very small rotors is not well established, and additionally, the residual unbalance in small diameter shafts is difficult to measure using conventional methods. Hence we have estimated the residual unbalance of $0.001 \mathrm{~kg} \mathrm{~mm}$ based on machining specs for the shaft. Figures 16(a) and 16(b) show the linear stability map of the system for the 1st and 2nd bending modes. Hard-mounted ball bearing supports impart very little damping to the rotor system. However, we have noted earlier that due to Coulomb damping between the interference fits the rotor damping is likely to be higher than provided by bearings alone. Hence we have analyzed the system with two levels of damping. Figure 16(a) shows the linear stability map for the system with ball bearing

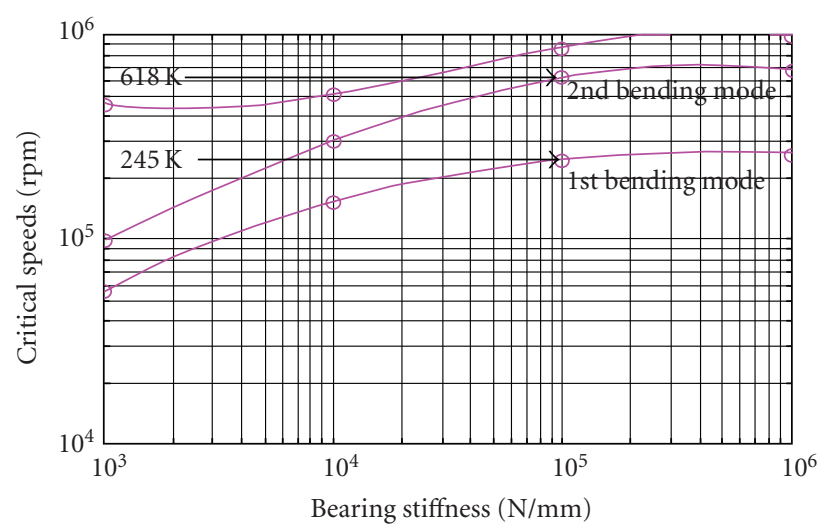

FIgURE 13: Critical speed map shows the variation of 1st, 2nd, and 3rd bending modes as a function of bearing stiffness (Stiffness is $\mathrm{N} / \mathrm{mm}$ ). At the assumed bearing stiffness of $100000 \mathrm{~N} / \mathrm{mm}$, the 1st and 2 nd bending critical speeds correspond to $\sim 245 \mathrm{~K} \mathrm{rpm}$ and $\sim 618 \mathrm{~K} \mathrm{rpm}$, respectively, as shown in Figures 11 and 12.

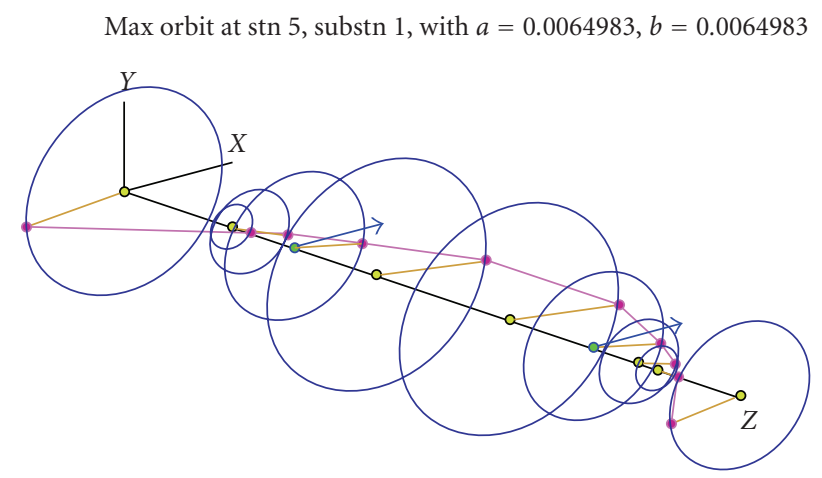

FIGURE 14: Unbalance response of shaft at $110 \mathrm{krpm}$. Maximum runout is $0.0065 \mathrm{~mm}$ at node 5 of the FE model.

support damping at $1 \mathrm{~N}$-sec/mm. The system is stable over the operating range, indicated by positive log decrements. Negative log decrement indicates instability in the system at that frequency. The system remains stable over the operating speed range at much lower levels of damping, as seen by the stability map in Figure 16(b) with a bearing damping of $0.01 \mathrm{~N}-\mathrm{sec} / \mathrm{mm}$.

\section{Thermal Modeling and Temperature Distribution Prediction}

A thermal model based on lumped parameter finite volume method associated with a software program created inhouse was used to predict the temperature distribution in the motor. The concept of electrical analog nodal network consisting of heat transfer resistance elements with boundary conditions is used. The motor components such as rotor, magnets, sleeve, windings, stator teeth, and back iron including the cooling channels for water or air are broken up into finite volumes. The number of volumes for discretization is decided on a trade-off between resolution and computation power. For example, the volumes are smaller where the 


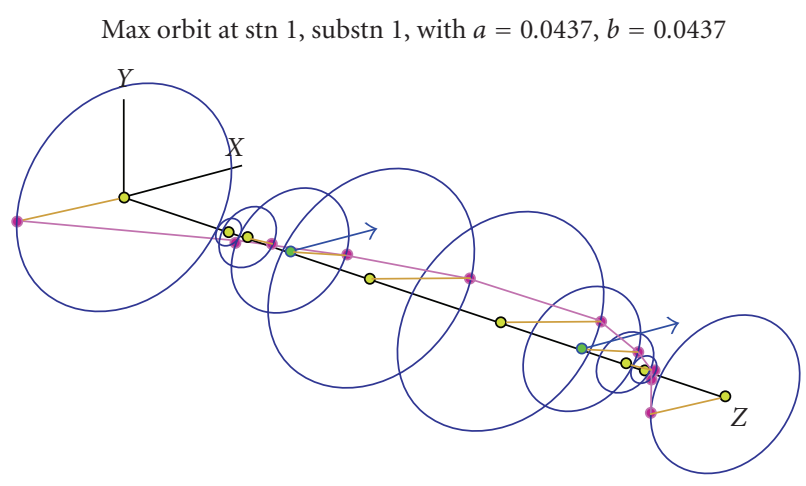

FIGURE 15: Unbalance response of shaft at $200 \mathrm{krpm}$. Maximum runout is $0.0437 \mathrm{~mm}$ at node 1 of the FE model.

temperature gradient is expected to be steep. The nodes represent the center of the finite volumes.

Heat conduction, for example, between copper nodes or between copper and insulation nodes, is governed by Fourier's Law of heat transfer. Effective thermal conductivity or equivalent thermal length is used in the network to represent heat conduction from copper through the insulation. For example, $\mathrm{Eq}_{\text {copper length }}=\left(\mathrm{k}_{\text {copper }} / \mathrm{k}_{\text {insulation }}\right)^{*}$ Insulation thickness in end turn. Heat transfer rate between solid and fluids nodes is given by

$$
q^{\prime \prime}=h A \Delta T
$$

Convective heat transfer coefficient $(h)$ between the solid node and fluid nodes is calculated from Colburn $J$-factor curves [8], using the relation

$$
J=f n\left[\left(\operatorname{Re}^{a}, \operatorname{Pr}^{b}\right) / N u\right]
$$

where $a$ and $b$ are associated constants based on available correlations for internal or external flow, channel shape, and laminar or turbulent flow. The actual cooling channel shapes in the motor have been approximated to standard shapes associated for the available correlations [9].

The flow over the stator winding can be approximated for laminar flow over a flat plate:

$$
N u_{x}=0.453\left(\operatorname{Re}_{x}\right)^{0.5}(\operatorname{Pr})^{0.33} .
$$

Again, the flow over the end turns may be approximated for cross flow over cylinder in cross flow [9], For instance, the forced cooling air flow from the nozzles pointing towards the end turn can be modeled using heat transfer concept of impinging jets [9].

Pressure drop in channels inside the motor was calculated using Moody's friction chart. Properties such as thermal conductivity, heat capacity, and density are considered and allocated to respective finite volumes for solid nodes.

Copper wires bundles are generally embedded in the insulation and then the whole composite is inserted in the motor slots. The heat transfer (conduction) from composite consisting of copper wires and insulation to the surrounding nodes of stator teeth and stator back iron was modeled using copper fill factor correction. Copper fill factor is defined as the ratio of total copper area to the winding window area. Copper, back iron, rotor, and bearing losses were allocated to the respective finite volumes. The total copper losses are allocated in proportion to number of conductors and length between end turn and stacks.

Windage loss [10-13], based on (4)-(7), was calculated in the thermal model as follows:

$$
\begin{gathered}
\operatorname{Re}=\omega \times r \times \phi^{*} \gamma, \\
T a=\operatorname{Re} \times\left(\frac{\phi}{r}\right)^{0.5}, \\
C_{d}=0.0095^{*}(\mathrm{Ta})^{-0.2}, \\
W=C_{d} \times \pi \times \rho \times \omega^{3} \times r^{4} \times l .
\end{gathered}
$$

The temperature distribution can be obtained at various nodes after an iterative process as in steady state. The energy balance in the model can be summarized as follows:

(i) Heat In = Total of copper, rotor, and core losses,

(ii) Heat Generated = Windage and bearing losses,

(iii) Heat Out $=$ Heat removed by water and air cooling,

(iv) Heat In + Heat Generated $=$ Heat Out.

The air flow over the end-turn may not be equally distributed. Even though combination of equally distributed nozzles and baffles maybe used, there may exists hot spots especially where the leads come out. The thermal model developed is 360 degree symmetric on the axis and therefore has shortcomings predicting those hot spots. It was therefore necessary to add safety factor to the calculated cooling flow rates. Figure 17 shows the pictorial representation of the thermal model shown.

(i) Node 1 is Rotor.

(ii) Node 2 is Samarium Cobalt Magnet.

(iii) Node 3 is plug.

(iv) Node 4 is Ceramic Ball bearing.

(v) Nodes 5 through 19 are copper winding nodes.

(vi) Nodes 11 and 12 are stator nodes.

(vii) Nodes 13 and 14 are water cooling jacket or housing nodes.

(viii) Nodes 120 and 121 are water cooling fluid nodes.

(ix) Nodes 100, 102, through 105 are air cooling nodes.

The temperature distribution predicted by the thermal model at $110,000 \mathrm{rpm}$ and at room temperature is shown in Figure 18. The thermal model showed that the majority of the heat input $(70 \%)$ is carried away by air. Windage calculated was $2 \mathrm{~W}$ and agreed quite well with (7). 


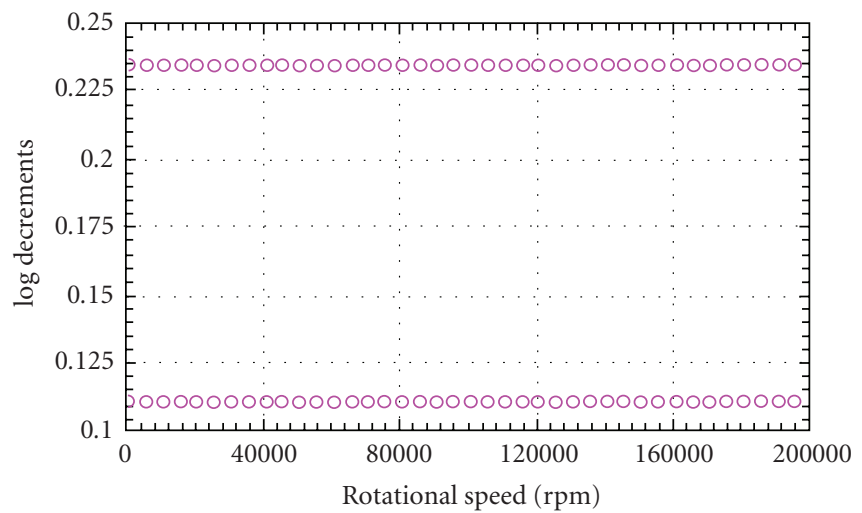

(a)

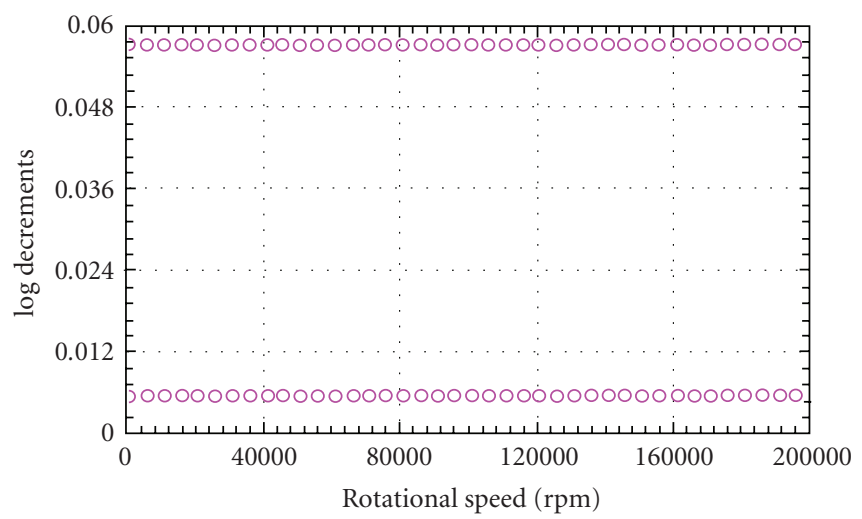

(b)

FIGURE 16: Linear stability map for 1 st and 2nd bending modes shown as a function of speed: (a) Bearing damping $=1 \mathrm{~N}-\mathrm{sec} / \mathrm{mm}$, and (b) Bearing damping $=0.01 \mathrm{~N}$-sec/mm. Positive log decrements indicate a stable system.

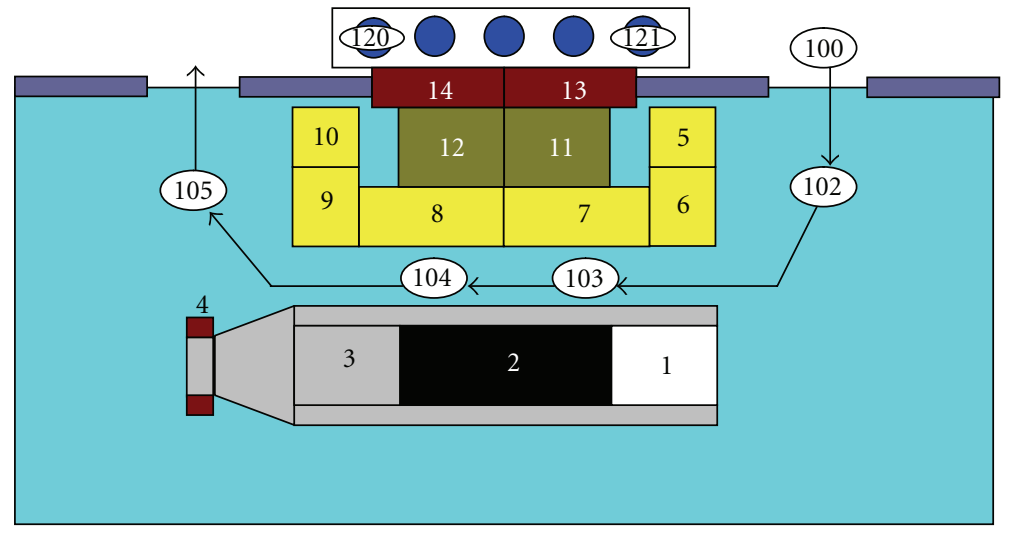

FIgURE 17: Node number scheme in a thermal model of the cryocooler system.

\section{Motor Generator Test Set-Up and Results}

Figures 4-6 show the fabricated motor parts including housing, two caps, the integrated rotor, and the stator with winding. The permanent magnet synchronous motor was tested successfully under no-load free-spin condition. The free-spin test is to spin the motor at a constant speed and measure the input power needed to keep the motor spinning. Since there is no mechanical load applied, the input power to the controller is equal to the losses in the system including windage loss, bearing loss, stator iron loss, and controller loss. Of these loss components, the bearing loss dominates when rotating at $200000 \mathrm{rpm}$. Figure 19 plots the input power to the controller as a function of motor speed, up to $200000 \mathrm{rpm}$. It shows that the input power increases gradually with the increase of rotating speed, and the electric motor operation is stable.

It was necessary to determine the efficiency of the motor and was required to run the motor under loaded conditions. A motor-generator set was built on a single titanium shaft. The structure had two permanent magnets, one working as motor and other working as generator. The motor and generator magnets were installed on the same shaft as no high-speed couplers were available to operate at $100000 \mathrm{rpm}$ [14]. Figure 20 shows the rotor components of the motorgenerator and Figure 21 shows the assembled rotor and the motor-generator housing.

Power resistors were connected to the generator side as power load. Figure 22 shows the motor efficiency versus motor speed for the motor-generator system, where the torque $(T)$ was calculated based on the output power and the rotating speed according to the following equation:

$$
T=\frac{P}{\omega},
$$

where $P$ is the output power and $\omega$ is the rotating angular frequency. The input power to the motor and output power from the generator were measured for each test speed. The total motor-generator set loss was obtained by subtracting the output power by the input power. The loss of the motor was further separated from the total motor-generator set loss assuming that the motor and the generator have the same efficiency. Therefore, the motor efficiency was calculated by accounting for the additional bearing loss which was 


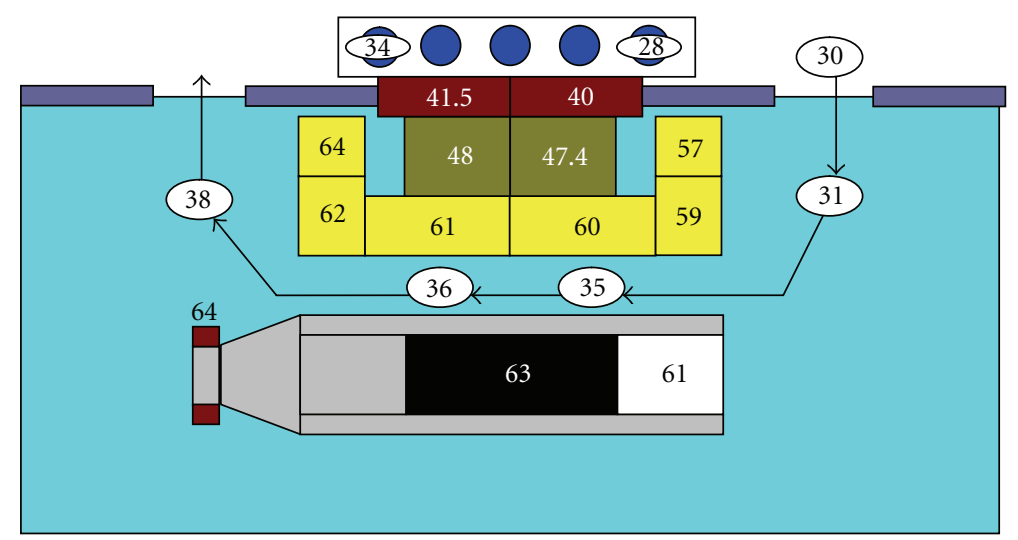

Figure 18: Temperature distribution at the thermal model nodal locations, in ${ }^{\circ} \mathrm{C}$.

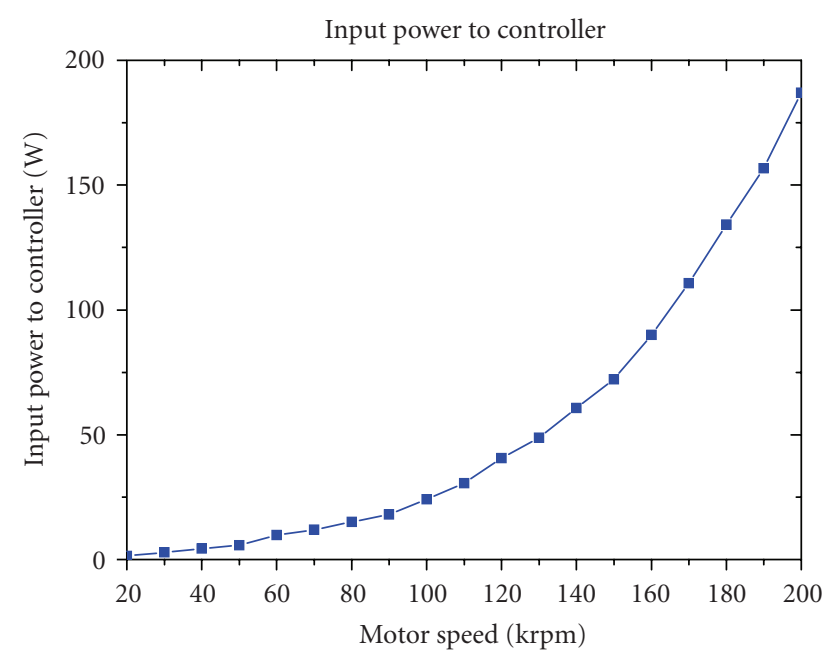

FIGURE 19: Measured input power to the controller as a function of shaft speed.

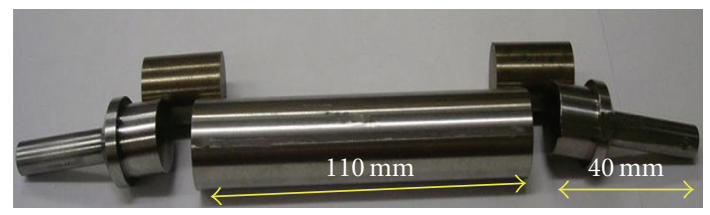

FIGURE 20: Rotor components of the motor-generator.

obtained using a spin-down test. Due to the limited load resistor values, the efficiencies were not measured at the constant torque condition as shown in Figure 22, where a lower load was applied at the lower speed, and a higher load was applied at the higher speed. At a given speed, at lowload conditions, required motor current is lower, resulting in low required torque and low winding temperature. When the torque is low, the efficiency is also low since some losses are relatively load-independent. However, with increasing torque, the winding temperature rises with consequent increase in $i^{2} R$ loss, resulting in a drop in efficiency. The optimized torque is $0.095 \mathrm{~N}-\mathrm{m}$ when the motor operates at $77 \mathrm{~K}$. At the room temperature, the torque corresponding to

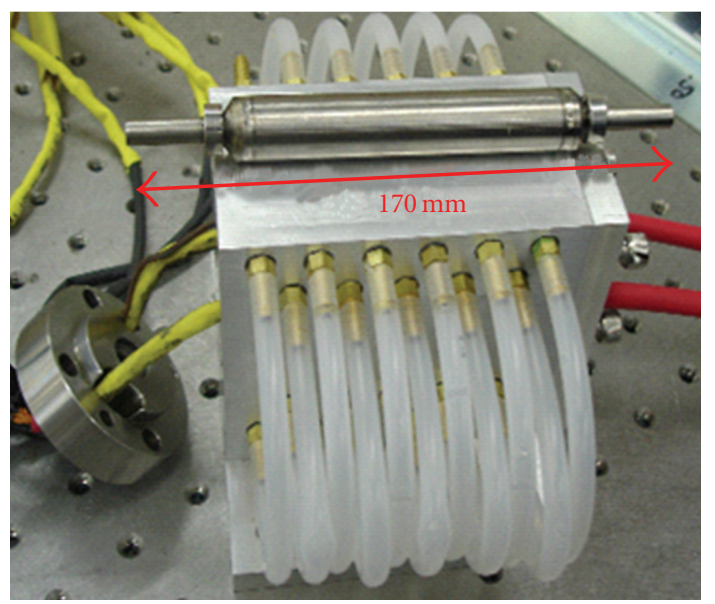

FIGURE 21: Assembled motor-generator rotor and housing.

the highest efficiency is $0.06 \mathrm{~N}-\mathrm{m}$, at ideal cooling conditions. The drop in torque and winding temperature at $61 \mathrm{Krpm}$ and the peak at $110 \mathrm{Krpm}$ in Figure 22 are due to a power resistor changes at those speeds. The torque could be increased by filling the gap between the stator winding and the housing with epoxy so that the heat generated at the winding can be removed more effectively and the efficiency will be fairly constant at $93 \%$.

Thermocouples mounted on the winding, stator core, housing, water outlet, and air outlet were monitored. Water and air flow rates were measured. Based on the experimental results at room temperature, good agreement with the structural, thermal, and rotordynamic models was observed. For example, at $110 \mathrm{Krpm}$, the winding temperature predicted by the thermal model is $60^{\circ} \mathrm{C}$ while the measured one is $59^{\circ} \mathrm{C}$. When the motor operates at $77 \mathrm{~K}$, the copper DC loss will reduce substantially due to reduced resistance at low temperature, and the stator core loss will increase slightly. The overall efficiency will be higher than at room temperature. An air bearing will be used for the test at $77 \mathrm{~K}$ since grease-lubricated ceramic ball bearings cannot be used for high-speed operation at $77 \mathrm{~K}$. 


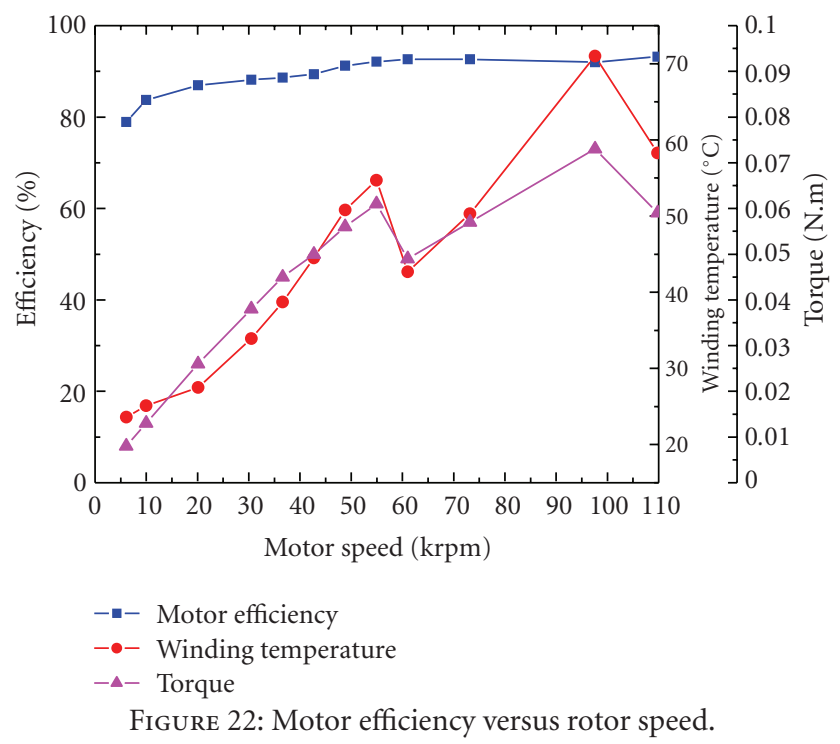

\section{Summary}

A comprehensive procedure for systems design, fabrication, and testing of a miniature high-speed $(200000 \mathrm{rpm}) 2 \mathrm{~kW}$ PMSM is presented. The motor is to be used as a power source for a miniature high-speed Reverse Turbo-Brayton Cryocooler (RTBC). The RTBC is considerably lighter than conventional designs and a potentially viable and attractive solution for NASA's long-term Zero-Boil-off (ZBO) hydrogen storage system for future space missions. The mechanical design entails detailed FE stress analysis of the hollow titanium rotor-permanent magnet system and an FE-based rotordynamic analysis for evaluating system critical speeds, unbalance response, and linear stability limits. The rotor shaft was designed to operate below the first bending critical speed. A thermal system model was built to predict temperature distribution in the system, which agreed well with measured temperatures by thermocouples located on winding, air inlet and outlet, water inlet and outlet, and housing. A motor-generator set was developed and a motor efficiency of $93 \%$ at $110,000 \mathrm{rpm}$ was obtained. The system operated in a stable fashion throughout the relevant speed range.

\section{Nomenclature}

Re: $\quad$ Reynolds number

Pr: $\quad$ Prandtl number

Nu: $\quad$ Nusselt number

$\omega: \quad$ Rotational velocity

$r: \quad$ Shaft radius

$\varphi: \quad$ Air gap

$v: \quad$ Kinematic viscosity of fluid

Ta: $\quad$ Taylor number

$C_{d}: \quad$ Drag coefficient

$l: \quad$ Rotor length

$h: \quad$ heat transfer coefficient

A : $\quad$ surface area

$\mathrm{k}_{\text {copper }}$ : Thermal conductivity of copper

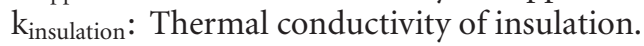

\section{Acknowledgment}

This work was supported by NASA Glenn through the Hydrogen Research for Florida Universities Program.

\section{References}

[1] L. Zhou, A miniature reverse-brayton cycle cryocooler and its key components: high effectiveness heat recuperator and miniature centrifugal compressor, Ph.D dissertation, University of Central Florida, Orlando, Fla, USA, 2004.

[2] L. Zheng, T. X. Wu, D. Acharya, et al., "Design of a superhigh speed cryogenic permanent magnet synchronous motor," IEEE Transactions on Magnetics, vol. 41, no. 10, pp. 3823-3825, 2005.

[3] L. Zhao, C. H. Ham, Q. Han, et al., "Design of optimal digital controller for stable super-high-speed permanentmagnet synchronous motor," IEE Proceedings Electric Power Applications, vol. 153, no. 2, pp. 213-218, 2006.

[4] O. E. Jones, D. Franklin, H. L. Horton, and H. H. Ryffel, Machinery's Handbook, Industrial Press, New York, NY, USA, 27th edition, 2004.

[5] Roarke Handbook of Stress and Strain, McGraw-Hill Professional, New York, NY, USA, 7th edition, 2001.

[6] J. R. Shigley, Mechanical Engineering Design, McGraw-Hill, New York, NY, USA, 1989.

[7] S. Timoshenko, Elements of Strength of Materials, Van Nostrand, Princeton, NJ, USA, 1962.

[8] W. M. Kays, M. Crawford, and B. Weigand, Convective Heat and Mass Transfer, McGraw-Hill, New York, NY, USA, 4th edition, 2004.

[9] F. P. Incropera, D. P. DeWitt, T. L. Bergman, and A. S. Lavine, Fundamentals of Heat and Mass Transfer, John Wiley \& Sons, Hoboken, NJ, USA, 6th edition, 2007.

[10] J. I. Provins and L. V. Lewis, "A non-coupled CFD-FE procedure to evaluate windage and heat transfer in rotorstator cavities," GT2004-53246.

[11] J. E. Vrancrik, "Prediction of windage power loss in alternators," Tech. Rep. TND-4849, NASA-Langey, 1968.

[12] C. Gazley Jr., "Heat-transfer characteristics of the rotational and axial flow between concentric cylinders," ASME Transactions, vol. 80, no. 1, pp. 79-90, 1958.

[13] T. Theodorsen and A. Regier, "Experiments on drag of revolving disks, cylinders and streamline rods at high speeds," Tech. Rep. NACA 793, 1944.

[14] G. H. F. Nayler, Dictionary of Mechanical Engineering, Butterworth-Heineman, Oxford, UK, 4th edition, 1996. 

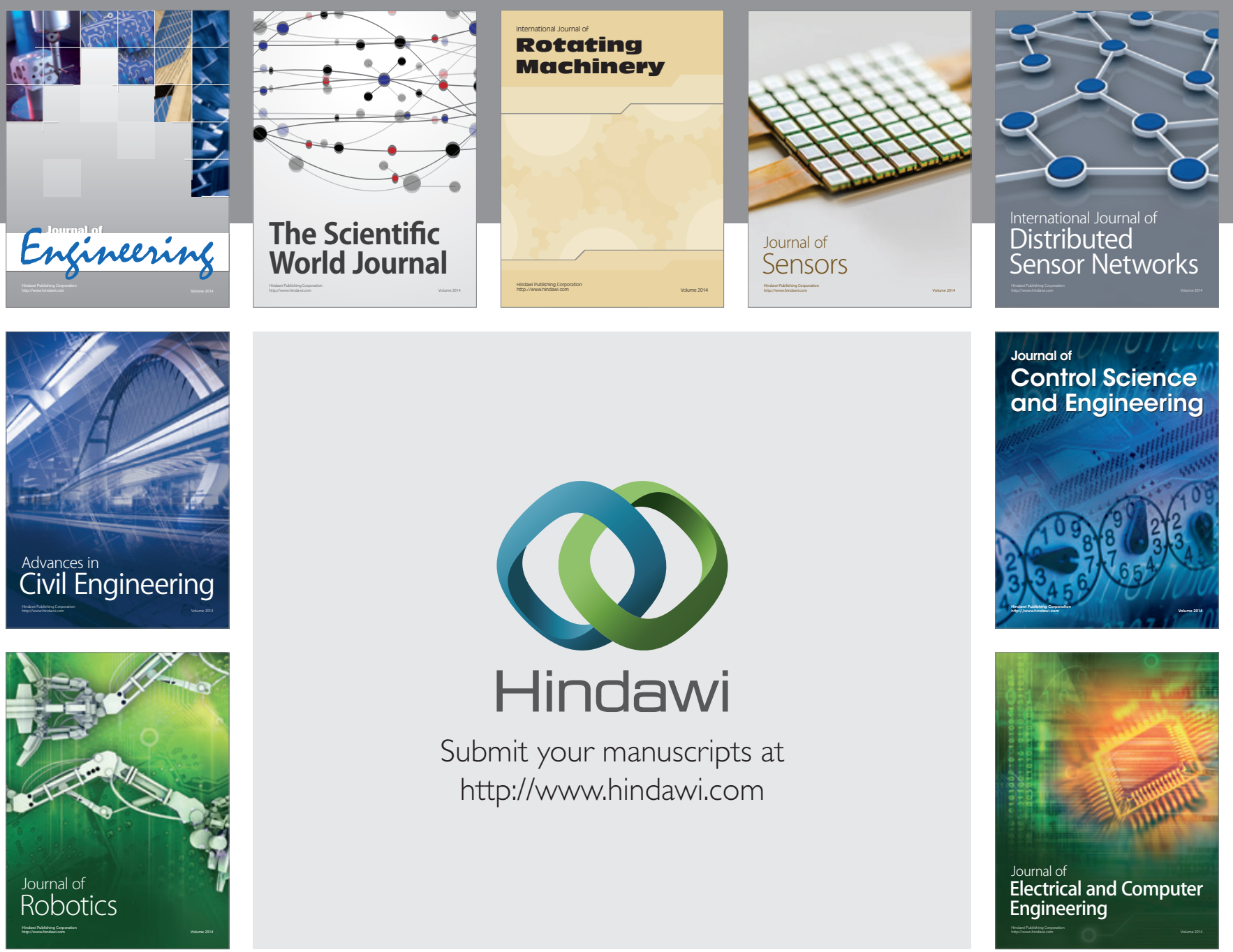

Submit your manuscripts at

http://www.hindawi.com
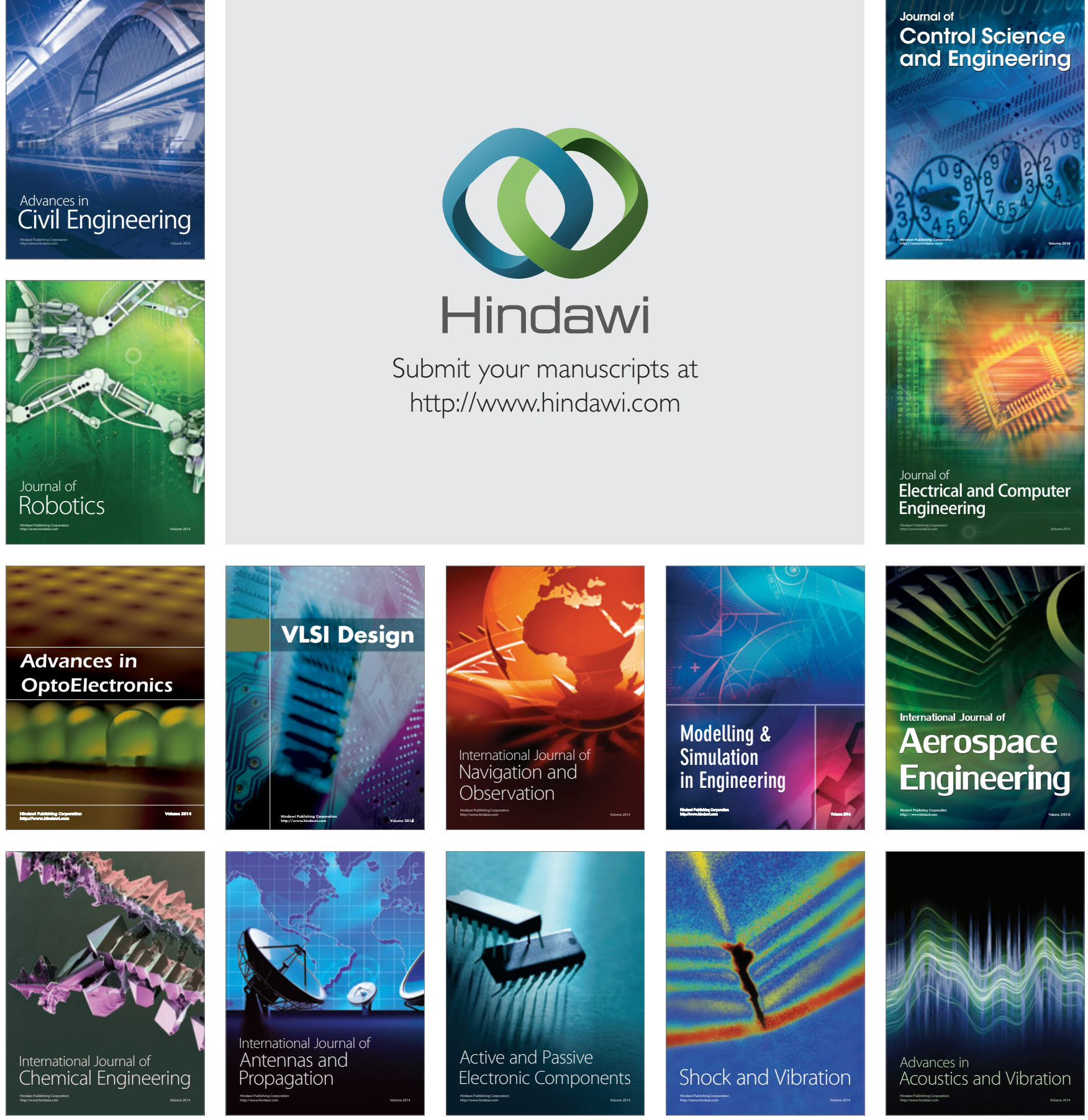